\title{
Gout in immigrant groups: a cohort study in Sweden
}

\author{
Per Wändell ${ }^{1}(1) \cdot$ Axel C Carlsson ${ }^{1,2} \cdot X^{3}$ jujun $\mathrm{Li}^{3} \cdot$ Danijela Gasevic $^{4} \cdot$ Johan Ärnlöv $^{2}$ • \\ Martin J Holzmann ${ }^{5,6}$ • Jan Sundquist ${ }^{3} \cdot$ Kristina Sundquist $^{3}$
}

Received: 7 November 2016/Revised: 19 December 2016/Accepted: 20 December 2016 /Published online: 13 January 2017

(C) The Author(s) 2017. This article is published with open access at Springerlink.com

\begin{abstract}
Our aim was to study the association between country of birth and incidence of gout in different immigrant groups in Sweden. The study population included the whole population of Sweden. Gout was defined as having at least one registered diagnosis in the National Patient Register. The association between incidence of gout and country of birth was assessed by Cox regression, with hazard ratios (HRs) and 95\% confidence intervals (95\% CI), using Swedish-born individuals as referents. All models were conducted in both men and women, and the full model was adjusted for age, place of residence in Sweden, educational level, marital status, neighbourhood socio-economic status and co-morbidities. The risk of gout varied by country of origin, with highest estimates, compared to Swedish born, in fully
\end{abstract}

Key messages 1 . We found both increased and decreased risk of gout in different immigrant groups compared to Swedish-born individuals.

2. Our findings with lower gout risk among immigrants from Southern Europe and Latin America suggest a possible preventive effect on gout by Mediterranean diet.

3. The increased risk of gout among several immigrant groups is likely explained by a high cardio-metabolic risk factor pattern needing attention.

Electronic supplementary material The online version of this article (doi:10.1007/s10067-016-3525-1) contains supplementary material, which is available to authorized users.

Per Wändell

per.wandell@ki.se

1 Department of Neurobiology, Care Sciences and Society, Division of Family Medicine, Karolinska Institutet, Alfred Nobels Allé 23, SE-141 83 Huddinge, Sweden

2 Department of Medical Sciences, Cardiovascular Epidemiology, Uppsala University, Uppsala, Sweden adjusted models among men from Iraq (HR 1.82, 95\% CI 1.54-2.16), and Russia (HR 1.69, 95\% CI 1.26-2.27), and also high among men from Austria, Poland, Africa and Asian countries outside the Middle East; and among women from Africa (HR 2.23, 95\% CI 1.50-3.31), Hungary (HR 1.98, 95\% CI 1.45-2.71), Iraq (HR 1.76, 95\% CI 1.13-2.74) and Austria (HR 1.70, 95\% CI 1.07-2.70), and also high among women from Poland. The risk of gout was lower among men from Greece, Spain, Nordic countries (except Finland) and Latin America and among women from Southern Europe, compared to their Swedish counterparts. The increased risk of gout among several immigrant groups is likely explained by a high cardio-metabolic risk factor pattern needing attention.
3 Center for Primary Health Care Research, Lund University, Malmö, Sweden

4 Usher Institute of Population Health Sciences and Informatics, College of Medicine and Veterinary Medicine, University of Edinburgh, Edinburgh, UK

5 Department of Emergency Medicine, Karolinska University Hospital, Huddinge, Sweden

6 Department of Internal Medicine Solna, Karolinska Institutet, Stockholm, Sweden 
Keywords First-generation immigrants · Gender · Gout . Neighbourhood · Second-generation immigrants ·

Socio-economic status

\section{Introduction}

Gout is the most common inflammatory arthritis where monosodium urate crystals are deposited in joints and soft tissues. Individuals with gout experience acute attacks of excruciating pain; and, if left untreated, gout may lead to debilitating complications such as chronic joint damage and renal insufficiency [1]. All these contribute to the poor patient's health-related quality of life [2].

In addition, gout is also associated with different metabolic conditions, such as insulin resistance [3], the metabolic syndrome and diabetes mellitus [4]. Besides, there is also a strong relationship between gout and hypertension and with antihypertensive diuretic treatment $[5,6]$, especially with thiazide diuretics [7, 8], and with other cardio-vascular diseases such as chronic heart failure [5] and chronic kidney disease [9]. Gout is also associated with an increased mortality risk, mainly through the increased risk of cardio-vascular diseases, including coronary heart disease [10].

As a metabolic disorder, gout is associated with several established risk factors according to epidemiological studies [11]: genetic factors, excess alcohol consumption [12] and with a purine-rich diet, especially with high rate of hypoxanthine, i.e. diets with animal meats, fish meats, organs such as liver and fish milt and yeast [13].

Recent review of epidemiological evidence has indicated that gout has risen worldwide over the last few decades [1], tailing the obesity epidemic [11]. Besides, the clinical picture of gout seems to have become more complex [11]. However, there is a large variation in the prevalence data of gout. Evidence from a recent review and meta-regression indicates that age, sex, continent on which study was performed and the case definition of gout accounted for the large variation in gout prevalence across studies [9]. Indeed, ageing is a risk factor for gout in both sexes; however, gout is more prevalent in men than in women $[14,15]$. Furthermore, there are significant differences in prevalence of gout across the continents where the highest prevalence with estimates of $>10 \%$ has been observed in Oceanian countries and a high prevalence of 14\% in most countries in North America and Western Europe [16]. Lower prevalence has been observed in former Soviet Union regions, Guatemala, Philippines, Malaysia, Iran, rural Turkey, Saud Arabia and African countries.

In Sweden, almost one fifth of the population is foreign born, and immigration to Sweden increases with each year [17]. Describing and better understanding of disparities in gout among immigrants are of great interest both for the health care and the society in general for possible preventive actions.
The aim of this study was to explore the risk of being diagnosed with gout among first- and second-generation immigrants in Sweden.

\section{Methods}

\section{Design}

The dataset used in this study was retrieved from governmental national registers such as the Total Population Register (TPR) and the National Patient Register (NPR) that contain longitudinal information on the entire population of Sweden for a period of 40 years. The TPR contains comprehensive nationwide individual-level data as well as data on neighbourhood socio-economic status (SES). The Swedish nationwide population and health care registers have exceptionally high completeness and validity [18]. Individuals were tracked using their personal identification numbers, which are assigned to each resident of Sweden. These identification numbers were replaced with serial numbers to provide anonymity. Subjects of 45 years of age and older were included in the study. The follow-up period ran from January 1, 1998 until hospitalization/outpatient treatment of gout at death, emigration or December 31, 2012, whichever came first.

\section{Study population and co-morbidities}

This study included the whole Swedish population. Country of birth was registered, and we included 10 regions (Nordic countries, Southern Europe, Western Europe, Eastern Europe, Baltic countries, Central Europe, Africa, North America, Latin America and Asia) and 27 countries (Supplementary Table 1). Countries with less than 10 observed cases of gout were not analysed separately. The second-generation immigrants were defined according to the Swedish Multi-generation Register, based on their parental immigrant's information.

The reference population in the analysis for the secondgeneration immigrants was Swedes in at least two generations that are adults 45 years of age and older born in Sweden and with both father and mother born in Sweden.

Patients with diagnosed gout were identified by the presence of the ICD-10 code (tenth version of the WHO's International Classification of Diseases) for gout (M10) in the National Patient Register. Patients with gout diagnosed before 1998, i.e. during the years 1987-1997 (according to ICD-9 1987-1996 and ICD-10 1997) were excluded.

We also identified co-morbidities according to ICD-10 for the following diagnoses: hypertension I10-I19, coronary heart disease (CHD) I20-I25, heart failure I50, stroke I60-I69, diabetes E10-E14, obesity E65-E68, alcoholism and related disorders F10 and K70 and chronic obstructive pulmonary disease (COPD) J40-J47. 


\section{Outcome variable}

Gout ICD-10 code M10.

\section{Demographic and socio-economic variables}

Sex: men and women.

Age was used as a continuous variable in the analysis.

Educational attainment was categorized as $\leq 9$ years (partial or complete compulsory schooling), 10-12 years (partial or complete secondary schooling) and $>12$ years (attendance at college and/or university).

Geographic region of residence was included in order to adjust for possible regional differences in hospital admissions and was categorized as (1) large cities, (2) southern Sweden and (3) northern Sweden. Large cities were defined as municipalities with a population of $>200,000$ and comprised the three largest cities in Sweden: Stockholm, Gothenburg and Malmö.

\section{Neighbourhood socio-economic status}

The neighbourhoods were derived from small-area market statistics (SAMS), which were originally created for commercial purposes and pertain to small geographic areas with boundaries defined by homogenous types of buildings. The average population in each SAMS neighbourhood is approximately 2000 people for Stockholm and 1000 people for the rest of Sweden. A summary index was calculated to characterize neighbourhood-level deprivation. The neighbourhood index was based on information about female and male residents aged 20 to 64 years, because this age group represents those who are among the most socio-economically active in the population (i.e. a group that has a stronger impact on the socioeconomic structure in the neighbourhood compared to children, younger women and men and retirees). The index was based on the following four variables: low educational status $(<10$ years of formal education); income from all sources, including interest and dividends, that is $<50 \%$ of the median individual income; unemployment (excluding full-time students, those completing military service and early retirees); and receipt of social welfare. The index was categorized into three groups: more than one standard deviation (SD) below the mean (high SES or low deprivation level), more than one SD above the mean (low SES or high deprivation level) and within one SD of the mean (middle SES or deprivation level) [19], with neighbourhood status classified as high, middle or low SES or on low, middle and high deprivation index [20].

\section{Statistical analysis}

Baseline subject characteristics were presented for population samples when estimating incidence rates of gout among firstgeneration immigrants and among second-generation immigrants.
Cox regression was used for estimating the risk for gout in different immigrant groups compared to Swedish born as referents. Time was from January 1, 1998, or immigration date until hospitalization/outpatient treatment of gout at diagnosis, death, emigration or the end of the study period on December 31, 2012.

All analyses were stratified by sex. Four models were used: model 1 was adjusted for age and region of residence in Sweden; model 2 was adjusted for age, region of residence in Sweden, educational level and marital status; model 3 was as model 2 with the addition of neighbourhood SES; and model 4 was as model 3 with the addition of co-morbidities. As a sensitive analysis, we also analysed hazard ratios (HRs) for first-generation immigrants with exclusion of immigrants who moved to Sweden within 5 years of follow-up with full adjustment according to model 4 .

The study was approved by the local ethical vetting board at the Karolinska Institutet (reference number 12/00 EPN Huddinge at 6 March 2000, approval of addition at 18 November 2002).

\section{Results}

Table 1 presents the characteristics of the included samples for first- and second-generation immigrants. Among the firstgeneration immigrants, $0.5 \%$ were diagnosed with gout, i.e. $0.8 \%$ among men and $0.3 \%$ among women, while among second-generation immigrants, $0.3 \%$ were diagnosed with gout. In general, the incidence of gout tended to be lower among both first- and second-generation immigrants than Swedish born, higher among lower educated and lower among higher educated, higher among residents in the larger cities and lower in northern Sweden and higher among individuals with co-morbidities, especially cardio-vascular comorbidities.

Table 2 presents risk of gout in first-generation male immigrants compared to their Swedish-born counterparts. After adjustment for age, region of residence in Sweden, educational level, marital status and neighbourhood deprivation (model 3) and compared to Swedish-born men, the risk of gout was higher among male immigrants with origin from Austria; Poland; Russia; and African and Asian continents, especially Iraq. In contrast, compared to Swedish-born men, the risk of gout was lower in men originating from Denmark; Norway; Southern Europe, especially Greece and Spain; and Latin America, especially Chile. After additional adjustment for co-morbidities (model 4), the estimates were somewhat attenuated but mostly with marginal changes.

Table 3 presents risk of gout in first-generation female immigrants compared to Swedish-born women. After adjustment for age, region of residence in Sweden, educational level, marital status and neighbourhood deprivation (model 3), 
Table 1 Population and number of cases of events (with percentages) in first generation and second generation

\begin{tabular}{|c|c|c|c|c|c|c|c|c|}
\hline & \multicolumn{4}{|c|}{ First generation } & \multicolumn{4}{|c|}{ Second generation } \\
\hline & \multicolumn{2}{|l|}{ Population } & \multicolumn{2}{|c|}{ Gout events } & \multicolumn{2}{|l|}{ Population } & \multicolumn{2}{|c|}{ Gout events } \\
\hline & No. & $\%$ & No. & $\%$ & No. & $\%$ & No. & $\%$ \\
\hline Total population & $6,449,369$ & & 32,956 & & $6,874,682$ & & 18,212 & \\
\hline \multicolumn{9}{|l|}{ Gender } \\
\hline Males & $3,051,102$ & 47.3 & 22,919 & 69.5 & $3,508,632$ & 51.0 & 14,511 & 79.7 \\
\hline Females & $3,398,267$ & 52.7 & 10,037 & 30.5 & $3,366,050$ & 49.0 & 3701 & 20.3 \\
\hline \multicolumn{9}{|l|}{ Immigrant status $^{\mathrm{a}}$} \\
\hline Sweden & $5,306,288$ & 82.3 & 28,900 & 87.7 & $5,666,670$ & 82.4 & 16,287 & 89.4 \\
\hline Other countries & $1,143,081$ & 17.7 & 4056 & 12.3 & $1,208,012$ & 17.6 & 1925 & 10.6 \\
\hline \multicolumn{9}{|l|}{ Birth year } \\
\hline-1909 & 79,034 & 1.2 & 328 & 1.0 & & & & \\
\hline 1910-19 & 349,829 & 5.4 & 3615 & 11.0 & & & & \\
\hline $1920-29$ & 628,432 & 9.7 & 8270 & 25.1 & & & & \\
\hline $1930-39$ & 733,408 & 11.4 & 7534 & 22.9 & 447,284 & 6.5 & 4246 & 23.3 \\
\hline $1940-49$ & $1,093,953$ & 17.0 & 6495 & 19.7 & $1,039,756$ & 15.1 & 6119 & 33.6 \\
\hline $1950-59$ & $1,027,898$ & 15.9 & 3702 & 11.2 & $1,035,473$ & 15.1 & 3812 & 20.9 \\
\hline $1960-69$ & $1,101,200$ & 17.1 & 2129 & 6.5 & $1,153,201$ & 16.8 & 2370 & 13.0 \\
\hline $1970-$ & $1,435,615$ & 22.3 & 883 & 2.7 & $3,198,968$ & 46.5 & 1665 & 9.1 \\
\hline \multicolumn{9}{|l|}{ Educational level } \\
\hline$\leq 9$ & $2,015,602$ & 31.3 & 15,352 & 46.6 & $1,772,765$ & 25.8 & 5894 & 32.4 \\
\hline $10-12$ & $1,628,711$ & 25.3 & 8570 & 26.0 & $1,476,803$ & 21.5 & 5791 & 31.8 \\
\hline$>12$ & $2,805,056$ & 43.5 & 9034 & 27.4 & $3,625,114$ & 52.7 & 6527 & 35.8 \\
\hline \multicolumn{9}{|l|}{ Region of residence } \\
\hline Large cities & $2,068,774$ & 32.1 & 13,444 & 40.8 & $2,046,576$ & 29.8 & 7463 & 41.0 \\
\hline Southern Sweden & $2,696,245$ & 41.8 & 14,039 & 42.6 & $2,653,219$ & 38.6 & 7619 & 41.8 \\
\hline Northern Sweden & $1,684,350$ & 26.1 & 5473 & 16.6 & $2,174,887$ & 31.6 & 3130 & 17.2 \\
\hline \multicolumn{9}{|l|}{ Marital status } \\
\hline Married & $4,758,618$ & 73.8 & 23,425 & 71.1 & $4,719,785$ & 68.7 & 10,860 & 59.6 \\
\hline Unmarried & $1,690,751$ & 26.2 & 9531 & 28.9 & $2,154,897$ & 31.3 & 7352 & 40.4 \\
\hline \multicolumn{9}{|c|}{ Neighbourhood deprivation } \\
\hline Low & 891,126 & 13.8 & 4420 & 13.4 & 939,288 & 13.7 & 2668 & 14.6 \\
\hline Middle & $3,043,079$ & 47.2 & 16,065 & 48.7 & $2,977,688$ & 43.3 & 8644 & 47.5 \\
\hline High & 722,008 & 11.2 & 3720 & 11.3 & 684,085 & 10.0 & 1979 & 10.9 \\
\hline Unknown & $1,793,156$ & 27.8 & 8751 & 26.6 & $2,273,621$ & 33.1 & 4921 & 27.0 \\
\hline \multicolumn{9}{|c|}{ Hospital diagnosis of COPD } \\
\hline No & $6,160,669$ & 95.5 & 28,777 & 87.3 & $6,598,004$ & 96.0 & 16,394 & 90.0 \\
\hline Yes & 288,700 & 4.5 & 4179 & 12.7 & 276,678 & 4.0 & 1818 & 10.0 \\
\hline \multicolumn{9}{|c|}{ Hospital diagnosis of obesity } \\
\hline No & $6,364,017$ & 98.7 & 31,844 & 96.6 & $6,768,237$ & 98.5 & 17,216 & 94.5 \\
\hline Yes & 85,352 & 1.3 & 1112 & 3.4 & 106,445 & 1.5 & 996 & 5.5 \\
\hline \multicolumn{9}{|c|}{ Hospital diagnosis of $\mathrm{CHD}$} \\
\hline No & $5,916,045$ & 91.7 & 22,145 & 67.2 & $6,656,575$ & 96.8 & 14,577 & 80.0 \\
\hline Yes & 533,324 & 8.3 & 10,811 & 32.8 & 218,107 & 3.2 & 3635 & 20.0 \\
\hline \multicolumn{9}{|c|}{ Hospital diagnosis of diabetes } \\
\hline No & $6,099,921$ & 94.6 & 26,181 & 79.4 & $6,656,003$ & 96.8 & 14,950 & 82.1 \\
\hline Yes & 349,448 & 5.4 & 6775 & 20.6 & 218,679 & 3.2 & 3262 & 17.9 \\
\hline \multicolumn{9}{|c|}{ Hospital diagnosis of alcoholism and related disorders } \\
\hline No & $6,313,123$ & 97.9 & 31,197 & 94.7 & $6,689,528$ & 97.3 & 16,531 & 90.8 \\
\hline
\end{tabular}


Table 1 (continued)

\begin{tabular}{|c|c|c|c|c|c|c|c|c|}
\hline & \multicolumn{4}{|c|}{ First generation } & \multicolumn{4}{|c|}{ Second generation } \\
\hline & \multicolumn{2}{|l|}{ Population } & \multicolumn{2}{|c|}{ Gout events } & \multicolumn{2}{|l|}{ Population } & \multicolumn{2}{|c|}{ Gout events } \\
\hline & No. & $\%$ & No. & $\%$ & No. & $\%$ & No. & $\%$ \\
\hline Yes & 136,246 & 2.1 & 1759 & 5.3 & 185,154 & 2.7 & 1681 & 9.2 \\
\hline \multicolumn{9}{|c|}{ Hospital diagnosis of stroke } \\
\hline No & $6,077,938$ & 94.2 & 27,275 & 82.8 & $6,741,870$ & 98.1 & 16,462 & 90.4 \\
\hline Yes & 371,431 & 5.8 & 5681 & 17.2 & 132,812 & 1.9 & 1750 & 9.6 \\
\hline \multicolumn{9}{|c|}{ Hospital diagnosis of hypertension } \\
\hline No & $5,689,298$ & 88.2 & 18,884 & 57.3 & $6,422,170$ & 93.4 & 11,053 & 60.7 \\
\hline Yes & 760,071 & 11.8 & 14,072 & 42.7 & 452,512 & 6.6 & 7159 & 39.3 \\
\hline \multicolumn{9}{|c|}{ Hospital diagnosis of heart failure } \\
\hline No & $6,126,173$ & 95.0 & 22,043 & 66.9 & $6,797,635$ & 98.9 & 15,298 & 84.0 \\
\hline Yes & 323,196 & 5.0 & 10,913 & 33.1 & 77,047 & 1.1 & 2914 & 16.0 \\
\hline
\end{tabular}

All differences between the population and patients diagnosed with gout were statistically significant $(p<0.001)$

${ }^{\text {a }}$ Immigrant status in second generation was based on parental birth country

the risk of gout was higher among immigrant women from Austria; Romania; Central Europe, especially Poland and Hungary; Africa and Asia, especially Turkey and Iraq; while a lower risk of gout was observed for immigrant women with origin not only from Southern Europe but also from North America compared to Swedish-born women. Additional adjustment for co-morbidities (model 4) attenuated the estimates, and these were no longer significant for women from Romania and Turkey and were with borderline significance among Polish women. When performing a sensitive analysis excluding immigrants who moved to Sweden within 5 years of follow-up, the estimates were very similar (Supplementary Tables 2 and 3).

Tables 4 and 5 present the risk of gout in second-generation male and female immigrants, respectively, compared to their Swedish-born counterparts. After adjusting for age, region of residence, educational level, marital status and neighbourhood SES (model 3), the risk of gout was higher among male immigrants with origin from the Nordic countries, especially Finland, and from Central Europe, especially Poland and in immigrants from the former Yugoslavia. In contrast, compared to Swedish-born men, the risk of gout was lower in men originating from Greece. Furthermore, secondgeneration immigrant women from the Nordic countries had lower risk for gout compared to their Swedish-born counterparts. With additional adjustment for co-morbidities (model 4), the estimates were somewhat attenuated.

\section{Discussion}

We explored the risk of being diagnosed with gout in first- and second-generation immigrant men and women than their
Swedish-born counterparts, with a total prevalence of $0.5 \%$. The most prominent differences in rates of gout were observed between first-generation immigrants and in Swedish-born people. Risk of being diagnosed with gout was higher not only among first-generation immigrants from several European countries but also among immigrants from Africa and some Asian countries, while the risk of being diagnosed with gout was lower among first-generation immigrants in some Southern European countries and among second-generation immigrant men from Greece. The differences in gout rates between the second-generation immigrant men and their Swedish-born counterparts were less apparent, while almost no difference was noted among women. The latter, however, may have been due to a low number of events.

When looking at the risk of gout among immigrants from European countries and the estimated prevalence in these countries, some interesting differences could be noted. Prevalence of gout is reported to be highest in Greece, with slightly lower figures from the UK, the Netherlands and Spain, while the lowest prevalence is reported from Portugal and the Czech Republic, with also low figures from France and Italy [16]. We found lower estimates for immigrants from Southern Europe, for men among first-generation immigrants from Greece and Spain, and among second-generation immigrants from Greece, in contrast to the reported prevalence figures from these countries. Low prevalence of gout in the world is reported from Asian countries, including the Middle East, African countries and at least from one country, i.e. Guatemala, in Latin America [16]. In contrast to these findings, we found higher gout risk among first-generation immigrants from Middle East countries and Africa.

We have no certain explanation for the disagreement between our study and earlier prevalence figures, e.g. the high 
Table 2 The risk of gout in firstgeneration male immigrants

\begin{tabular}{|c|c|c|c|c|}
\hline Country/region of origin & $\begin{array}{l}\text { Model } 1 \\
\text { HR }(95 \% \text { CI) }\end{array}$ & $\begin{array}{l}\text { Model } 2 \\
\text { HR }(95 \% \text { CI })\end{array}$ & $\begin{array}{l}\text { Model } 3 \\
\text { HR (95\% CI) }\end{array}$ & $\begin{array}{l}\text { Model } 4 \\
\text { HR }(95 \% \text { CI) }\end{array}$ \\
\hline Sweden & 1 (ref) & 1 (ref) & 1 (ref) & 1 (ref) \\
\hline Nordic countries & $0.93(0.87-0.99)$ & $0.92(0.86-0.98)$ & $0.94(0.88-1.00)$ & $0.87(0.82-0.93)$ \\
\hline Denmark & $0.75(0.64-0.88)$ & $0.74(0.64-0.87)$ & $0.75(0.64-0.88)$ & $0.76(0.65-0.89)$ \\
\hline Finland & $1.05(0.90-1.13)$ & $1.03(0.95-1.10)$ & $1.06(0.98-1.14)$ & $0.94(0.87-1.01)$ \\
\hline Norway & $0.70(0.58-0.85)$ & $0.71(0.59-0.85)$ & $0.72(0.60-0.87)$ & $0.74(0.62-0.90)$ \\
\hline Southern Europe & $0.65(0.55-0.78)$ & $0.65(0.54-0.77)$ & $0.67(0.56-0.80)$ & $0.74(0.62-0.88)$ \\
\hline France & $0.72(0.42-1.24)$ & $0.74(0.43-1.28)$ & $0.77(0.45-1.33)$ & $0.81(0.47-1.40)$ \\
\hline Greece & $0.46(0.33-0.63)$ & $0.45(0.32-0.62)$ & $0.47(0.34-0.65)$ & $0.54(0.39-0.76)$ \\
\hline Italy & $0.87(0.65-1.15)$ & $0.86(0.65-1.14)$ & $0.89(0.67-1.18)$ & $0.91(0.68-1.20)$ \\
\hline Spain & $0.50(0.29-0.87)$ & $0.49(0.29-0.85)$ & $0.51(0.30-0.89)$ & $0.57(0.33-0.98)$ \\
\hline Other Southern Europe & $1.03(0.64-1.66)$ & $1.02(0.63-1.64)$ & $1.03(0.64-1.66)$ & $1.16(0.72-1.87)$ \\
\hline Western Europe & $1.08(0.97-1.21)$ & $1.11(0.99-1.24)$ & $1.13(1.01-1.26)$ & $1.14(1.02-1.28)$ \\
\hline The Netherlands & $0.60(0.35-1.03)$ & $0.62(0.36-1.06)$ & $0.63(0.37-1.09)$ & $0.66(0.38-1.14)$ \\
\hline UK and Ireland & $1.03(0.80-1.33)$ & $1.06(0.82-1.37)$ & $1.10(0.85-1.42)$ & $1.24(0.96-1.61)$ \\
\hline Germany & $1.11(0.96-1.29)$ & $1.14(0.99-1.32)$ & $1.16(1.00-1.34)$ & $1.13(0.98-1.31)$ \\
\hline Austria & $1.41(1.08-1.85)$ & $1.45(1.10-1.90)$ & $1.48(1.13-1.95)$ & $1.42(1.08-1.87)$ \\
\hline Other Western Europe & $0.79(0.40-1.40)$ & $0.82(0.47-1.45)$ & $0.85(0.48-1.50)$ & $0.89(0.51-1.57)$ \\
\hline Eastern Europe & $1.08(0.97-1.21)$ & $1.09(0.98-1.22)$ & $1.11(1.00-1.25)$ & $1.03(0.92-1.15)$ \\
\hline Bosnia & $0.96(0.72-1.29)$ & $1.02(0.76-1.37)$ & $1.11(0.83-1.49)$ & $0.86(0.64-1.16)$ \\
\hline Yugoslavia & $1.09(0.95-1.25)$ & $1.08(0.94-1.24)$ & $1.09(0.95-1.26)$ & $1.03(0.90-1.19)$ \\
\hline Croatia & $1.46(0.95-2.25)$ & $1.46(0.95-2.24)$ & $1.45(0.94-2.22)$ & $1.47(0.96-2.26)$ \\
\hline Romania & $1.42(1.02-1.99)$ & $1.46(1.05-2.05)$ & $1.48(1.06-2.07)$ & $1.39(0.99-1.95)$ \\
\hline Baltic countries & $0.83(0.63-1.08)$ & $0.85(0.65-1.11)$ & $0.86(0.66-1.13)$ & $0.83(0.63-1.09)$ \\
\hline Estonia & $0.78(0.58-1.06)$ & $0.80(0.59-1.08)$ & $0.81(0.60-1.10)$ & $0.78(0.58-1.06)$ \\
\hline Latvia & $1.07(0.60-1.94)$ & $1.12(0.62-2.02)$ & $1.14(0.63-2.06)$ & $1.08(0.60-1.95)$ \\
\hline Central Europe & $1.25(1.09-1.43)$ & $1.28(1.12-1.46)$ & $1.29(1.13-1.47)$ & $1.18(1.04-1.35)$ \\
\hline Poland & $1.38(1.14-1.66)$ & $1.41(1.17-1.70)$ & $1.42(1.18-1.72)$ & $1.31(1.08-1.58)$ \\
\hline Other Central Europe & $1.01(0.72-1.42)$ & $1.05(0.75-1.48)$ & $1.06(0.75-1.49)$ & $1.01(0.72-1.42)$ \\
\hline Hungary & $1.22(0.98-1.51)$ & $1.24(1.00-1.54)$ & $1.24(1.00-1.55)$ & $1.12(0.90-1.40)$ \\
\hline Africa & $1.33(1.12-1.59)$ & $1.34(1.12-1.59)$ & $1.40(1.17-1.67)$ & $1.36(1.14-1.63)$ \\
\hline Northern America & $0.80(0.60-1.07)$ & $0.83(0.62-1.11)$ & $0.86(0.64-1.14)$ & $0.91(0.68-1.22)$ \\
\hline Latin America & $0.59(0.46-0.76)$ & $0.59(0.45-0.76)$ & $0.61(0.47-0.78)$ & $0.66(0.51-0.85)$ \\
\hline Chile & $0.48(0.33-0.68)$ & $0.47(0.33-0.67)$ & $0.48(0.34-0.69)$ & $0.52(0.36-0.74)$ \\
\hline South America & $0.78(0.55-1.12)$ & $0.79(0.55-1.13)$ & $0.82(0.57-1.17)$ & $0.91(0.64-1.31)$ \\
\hline Asia & $1.28(1.18-1.40)$ & $1.30(1.19-1.42)$ & $1.35(1.24-1.47)$ & $1.28(1.17-1.39)$ \\
\hline Turkey & $0.91(0.73-1.13)$ & $0.89(0.71-1.11)$ & $0.93(0.75-1.16)$ & $0.89(0.71-1.11)$ \\
\hline Lebanon & $1.03(0.75-1.43)$ & $1.01(0.73-1.39)$ & $1.04(0.75-1.44)$ & $0.99(0.72-1.37)$ \\
\hline Iran & $1.10(0.91-1.33)$ & $1.15(0.95-1.39)$ & $1.17(0.97-1.42)$ & $1.20(1.00-1.45)$ \\
\hline Iraq & $2.00(1.69-2.37)$ & $2.10(1.77-2.48)$ & $2.22(1.87-2.63)$ & $1.82(1.54-2.16)$ \\
\hline Other Asia countries & $1.37(1.18-1.59)$ & $1.39(1.20-1.61)$ & $1.44(1.24-1.67)$ & $1.37(1.18-1.59)$ \\
\hline Russia & $1.87(1.39-2.50)$ & $1.91(1.43-2.56)$ & $1.95(1.46-2.62)$ & $1.69(1.26-2.27)$ \\
\hline
\end{tabular}

Regions (also including separately listed countries) marked by italicsHR (95\% CI): Hazard ratios with 95\% confidence intervalStatistically significant HRs marked by italicsModel 1: adjusted for age and region of residence in Sweden; model 2: adjusted for age, region of residence in Sweden, educational level and marital status; model 3: model $2+$ neighbourhood deprivation; model 4: model $3+$ co-morbidities gout prevalence in Greece and the low gout risk among Greek immigrants we found. However, emigrants from a specific country or region may differ from those staying in their country of origin, i.e. migrants often tend to be healthier (the "healthy migrant effect"), even if many immigrants retain many of their dietary habits. The low estimates in some groups 
Table 3 The risk of gout in firstgeneration female immigrants

\begin{tabular}{|c|c|c|c|c|}
\hline Country/region of origin & $\begin{array}{l}\text { Model } 1 \\
\text { HR }(95 \% \text { CI) }\end{array}$ & $\begin{array}{l}\text { Model } 2 \\
\text { HR }(95 \% \text { CI) }\end{array}$ & $\begin{array}{l}\text { Model } 3 \\
\text { HR (95\% CI) }\end{array}$ & $\begin{array}{l}\text { Model } 4 \\
\text { HR }(95 \% \text { CI) }\end{array}$ \\
\hline Sweden & 1 (ref) & 1 (ref) & 1 (ref) & 1 (ref) \\
\hline Nordic countries & $1.05(0.97-1.15)$ & $1.01(0.93-1.10)$ & $1.03(0.94-1.12)$ & $0.94(0.87-1.03)$ \\
\hline Denmark & $0.96(0.76-1.21)$ & $0.93(0.74-1.17)$ & $0.93(0.74-1.17)$ & $0.96(0.76-1.21)$ \\
\hline Finland & $1.14(1.03-1.26)$ & $1.09(0.98-1.20)$ & $1.11(1.01-1.23)$ & $0.98(0.89-1.09)$ \\
\hline Norway & $0.88(0.71-1.09)$ & $0.85(0.69-1.06)$ & $0.86(0.69-1.06)$ & $0.82(0.66-1.02)$ \\
\hline Southern Europe & $0.53(0.35-0.81)$ & $0.50(0.33-0.76)$ & $0.52(0.52-0.78)$ & $0.61(0.40-0.93)$ \\
\hline Western Europe & $1.05(0.88-1.25)$ & $1.09(0.91-1.30)$ & $1.11(0.93-1.33)$ & $1.09(0.91-1.30)$ \\
\hline The Netherlands & $0.71(0.27-1.90)$ & $0.75(0.28-2.00)$ & $0.78(0.29-2.07)$ & $0.84(0.32-2.24)$ \\
\hline Germany & $1.05(0.85-1.29)$ & $1.09(0.88-1.34)$ & $1.11(0.90-1.36)$ & $1.04(0.84-1.28)$ \\
\hline Austria & $1.68(1.06-2.67)$ & $1.74(1.10-2.77)$ & $1.77(1.12-2.82)$ & $1.70(1.07-2.70)$ \\
\hline Eastern Europe & $1.26(1.02-1.57)$ & $1.19(0.96-1.48)$ & $1.21(0.97-1.50)$ & $1.10(0.89-1.36)$ \\
\hline Bosnia & $1.33(0.77-2.30)$ & $1.34(0.78-2.32)$ & $1.47(0.85-2.54)$ & $1.17(0.68-2.02)$ \\
\hline Yugoslavia & $1.14(0.86-1.50)$ & $1.04(0.79-1.38)$ & $1.04(0.79-1.38)$ & $0.96(0.73-1.27)$ \\
\hline Romania & $1.86(1.06-3.28)$ & $2.00(1.14-3.53)$ & $2.02(1.14-3.55)$ & $1.72(0.98-3.04)$ \\
\hline Baltic countries & $0.87(0.61-1.24)$ & $0.94(0.66-1.34)$ & $0.96(0.67-1.37)$ & $0.89(0.63-1.27)$ \\
\hline Estonia & $0.73(0.48-1.11)$ & $0.78(0.51-1.18)$ & $0.80(0.52-1.21)$ & $0.75(0.49-1.13)$ \\
\hline Central Europe & $1.55(1.27-1.88)$ & $1.65(1.36-2.01)$ & $1.65(1.36-2.01)$ & $1.47(1.21-1.79)$ \\
\hline Poland & $1.42(1.08-1.87)$ & $1.50(1.14-1.98)$ & $1.50(1.14-1.98)$ & $1.34(1.01-1.76)$ \\
\hline Other Central Europe & $1.00(0.57-1.76)$ & $1.09(0.62-1.92)$ & $1.10(0.62-1.94)$ & $1.06(0.60-1.86)$ \\
\hline Hungary & $2.20(1.61-3.01)$ & $2.34(1.71-3.21)$ & $2.34(1.71-3.21)$ & $1.98(1.45-2.71)$ \\
\hline Africa & $2.32(1.57-3.44)$ & $2.15(1.45-3.19)$ & $2.27(1.53-3.36)$ & $2.23(1.50-3.31)$ \\
\hline Northern America & $0.36(0.18-0.72)$ & $0.37(0.19-0.74)$ & $0.38(0.19-0.76)$ & $0.41(0.21-0.83)$ \\
\hline Latin America & $0.82(0.52-1.29)$ & $0.80(0.51-1.25)$ & $0.82(0.52-1.28)$ & $0.83(0.53-1.30)$ \\
\hline Chile & $0.90(0.51-1.59)$ & $0.85(0.48-1.50)$ & $0.87(0.49-1.53)$ & $0.84(0.47-1.47)$ \\
\hline Asia & $1.40(1.16-1.69)$ & $1.31(1.08-1.58)$ & $1.35(1.11-1.63)$ & $1.20(0.99-1.45)$ \\
\hline Turkey & $1.66(1.16-2.37)$ & $1.41(0.99-2.03)$ & $1.46(1.02-2.09)$ & $1.16(0.81-1.66)$ \\
\hline Iraq & $2.19(1.41-3.41)$ & $2.12(1.36-3.30)$ & $2.28(1.46-3.55)$ & $1.76(1.13-2.74)$ \\
\hline Other Asia countries & $1.36(1.01-1.84)$ & $1.29(0.96-1.75)$ & $1.33(0.99-1.80)$ & $1.30(0.96-1.75)$ \\
\hline Russia & $0.87(0.49-1.53)$ & $0.93(0.53-1.63)$ & $0.94(0.53-1.66)$ & $0.84(0.48-1.49)$ \\
\hline
\end{tabular}

Regions (also including separately listed countries) marked by italicsHR (95\% CI): Hazard ratios with $95 \%$ confidence intervalStatistically significant HRs marked by italics Model 1: adjusted for age and region of residence in Sweden; model 2: adjusted for age, region of residence in Sweden, educational level and marital status; model 3: model 2 + neighbourhood deprivation; model 4: model 3 + co-morbidities could possibly be related to the healthy migrant effect, e.g. men from Denmark and Norway and women from Northern America. For second-generation immigrants, an adaptation to the mainstream dietary culture could be expected, which could explain the regression towards the reference population, i.e. individuals with indigenous parents. Besides, comparing prevalence figures between studies of diagnosed gout in published papers is difficult, as there is a large variation in the prevalence of gout depending on different factors, including the used definition of gout, the sampling methods, the studied age groups and the sex distribution, with a higher prevalence in men [9, 21]. For instance, we emphasize that the gout prevalence of $0.5 \%$ in the present study is in accordance with the prevalence figure worldwide found in a review, which is $0.6 \%$ [9]. The prevalence in the present study was based on a hospital diagnosis of gout. A similar prevalence was found in an earlier Swedish study on reported diagnosis of gout from all care branches, i.e. hospital in-care, specialized open care and primary care [22]. However, in that study, the prevalence was $1.4 \%$ when including all individuals ever reported with a gout diagnosis including from primary health care being alive at the end of the study period [22], i.e. around the same prevalence as in the UK and Germany [15], and on the same level as in North America and other countries in Western Europe [16].

Regarding the situation among different immigrant groups, the higher gout prevalence in different ethnic groups, including Filipinos and African Americans, has been attributed to the high gout prevalence in North America [23]. The higher risk of hyperuricemia and gout as described among Filipinos in the USA is ascribed to the shift from a low-purine diet to a 
Table 4 The risk of gout in second-generation male immigrants

\begin{tabular}{|c|c|c|c|c|}
\hline Country/region of origin & $\begin{array}{l}\text { Model } 1 \\
\text { HR }(95 \% \text { CI) }\end{array}$ & $\begin{array}{l}\text { Model } 2 \\
\text { HR (95\% CI) }\end{array}$ & $\begin{array}{l}\text { Model } 3 \\
\text { HR (95\% CI) }\end{array}$ & $\begin{array}{l}\text { Model } 4 \\
\text { HR (95\% CI) }\end{array}$ \\
\hline Sweden & 1 (ref) & & & \\
\hline Nordic countries & $1.23(1.15-1.32)$ & $1.20(1.23-1.29)$ & $1.18(1.11-1.26)$ & $1.17(1.10-1.25)$ \\
\hline Denmark & $1.08(0.92-1.27)$ & $1.06(0.90-1.25)$ & $1.07(0.91-1.25)$ & $1.12(0.95-1.31)$ \\
\hline Finland & $1.34(1.23-1.45)$ & $1.29(1.19-1.41)$ & $1.26(1.16-1.37)$ & $1.23(1.13-1.33)$ \\
\hline Norway & $1.14(0.99-1.31)$ & $1.13(0.98-1.30)$ & $1.12(0.97-1.29)$ & $1.11(0.96-1.28)$ \\
\hline Southern Europe & $0.93(0.70-1.23)$ & $0.92(0.70-1.22)$ & $0.89(0.67-1.18)$ & $0.97(0.73-1.28)$ \\
\hline Greece & $0.47(0.24-0.95)$ & $0.46(0.23-0.93)$ & $0.44(0.22-0.89)$ & $0.50(0.25-1.00)$ \\
\hline Italy & $1.34(0.89-2.01)$ & $1.32(0.88-1.99)$ & $1.28(0.85-1.93)$ & $1.39(0.92-2.09)$ \\
\hline Spain & $1.45(0.80-2.62)$ & $1.43(0.79-2.59)$ & $1.38(0.77-2.50)$ & $1.45(0.80-2.62)$ \\
\hline Western Europe & $0.96(0.82-1.12)$ & $0.98(0.84-1.14)$ & $0.96(0.82-1.12)$ & $1.00(0.86-1.17)$ \\
\hline The Netherlands & $0.83(0.41-1.66)$ & $0.84(0.42-1.68)$ & $0.83(0.41-1.65)$ & $0.89(0.45-1.78)$ \\
\hline UK and Ireland & $0.63(0.36-1.12)$ & $0.65(0.37-1.15)$ & $0.63(0.36-1.12)$ & $0.65(0.37-1.15)$ \\
\hline Germany & $1.01(0.84-1.21)$ & $1.02(0.85-1.22)$ & $1.01(0.84-1.21)$ & $1.05(0.88-1.26)$ \\
\hline Austria & $1.28(0.85-1.93)$ & $1.31(0.87-1.97)$ & $1.28(0.85-1.93)$ & $1.31(0.87-1.98)$ \\
\hline Eastern Europe & $1.21(0.97-1.52)$ & $1.23(0.98-1.54)$ & $1.21(0.97-1.51)$ & $1.18(0.95-1.48)$ \\
\hline Yugoslavia & $1.31(1.02-1.70)$ & $1.30(1.01-1.67)$ & $1.30(1.00-1.67)$ & $1.28(0.99-1.65)$ \\
\hline Romania & $1.47(0.73-2.93)$ & $1.52(0.76-3.03)$ & $1.49(0.75-2.99)$ & $1.42(0.71-2.85)$ \\
\hline Baltic countries & $1.17(0.93-1.47)$ & $1.20(0.96-1.51)$ & $1.17(0.93-1.47)$ & $1.20(0.96-1.51)$ \\
\hline Estonia & $1.15(0.90-1.48)$ & $1.18(0.92-1.51)$ & $1.15(0.90-1.48)$ & $1.20(0.93-1.53)$ \\
\hline Latvia & $1.29(0.73-2.27)$ & $1.34(0.76-2.36)$ & $1.31(0.75-2.31)$ & $1.25(0.71-2.20)$ \\
\hline Central Europe & $1.37(1.11-1.69)$ & $1.40(1.13-1.72)$ & $1.39(1.13-1.72)$ & $1.36(1.10-1.68)$ \\
\hline Poland & $1.46(1.09-1.96)$ & $1.52(1.13-2.03)$ & $1.51(1.13-2.02)$ & $1.45(1.08-1.94)$ \\
\hline Other Central Europe & $1.20(0.72-1.98)$ & $1.22(0.74-2.03)$ & $1.21(0.73-2.01)$ & $1.24(0.75-2.05)$ \\
\hline Hungary & $1.37(0.94-1.98)$ & $1.36(0.94-1.97)$ & $1.36(0.94-1.97)$ & $1.34(0.92-1.94)$ \\
\hline North America & $0.99(0.75-1.29)$ & $1.01(0.77-1.32)$ & $1.00(0.76-1.30)$ & $1.02(0.78-1.34)$ \\
\hline Latin America & $0.70(0.41-1.18)$ & $0.70(0.42-1.19)$ & $0.68(0.40-1.15)$ & $0.66(0.39-1.11)$ \\
\hline South America & $1.11(0.58-2.14)$ & $1.15(0.60-2.21)$ & $1.12(0.58-2.15)$ & $1.11(0.58-2.13)$ \\
\hline Asia & $1.02(0.81-1.27)$ & $1.04(0.83-1.30)$ & $1.00(0.80-1.25)$ & $0.95(0.76-1.19)$ \\
\hline Turkey & $0.95(0.63-1.44)$ & $0.93(0.61-1.40)$ & $0.89(0.59-1.35)$ & $0.89(0.59-1.34)$ \\
\hline Iran & $1.12(0.65-1.93)$ & $1.20(0.69-2.06)$ & $1.17(0.68-2.01)$ & $1.07(0.62-1.84)$ \\
\hline Iraq & $1.34(0.76-2.36)$ & $1.45(0.82-2.56)$ & $1.34(0.76-2.36)$ & $1.15(0.65-2.03)$ \\
\hline Other Asian countries & $1.10(0.76-1.59)$ & $1.14(0.79-1.66)$ & $1.10(0.76-1.60)$ & $1.07(0.74-1.55)$ \\
\hline Russia & $0.85(0.53-1.37)$ & $0.86(0.53-1.38)$ & $0.85(0.53-1.36)$ & $0.82(0.51-1.32)$ \\
\hline
\end{tabular}

Regions (also including separately listed countries) marked by italicsHR (95\% CI): Hazard ratios with 95\% confidence intervalStatistically significant HRs marked by italics Model 1: adjusted for age and region of residence in Sweden; model 2: adjusted for age, region of residence in Sweden, educational level and marital status; model 3: model $2+$ neighbourhood deprivation; model 4: model 3 + co-morbidities high-purine Western diet, and the Filipino group seems to be especially vulnerable when adapting a high-purine diet [23].

When trying to understand the risk pattern of gout among the immigrant groups found in our study, the pattern of risk factors for gout is of importance. Gout is strongly related to lifestyle and dietary habits [24], including alcohol intake [12]. Trends in lifestyle factors, such as the increased alcohol intake [25], and change in dietary habits, including higher intake of sweetened soft drinks [21], contribute to increased obesity and the metabolic syndrome in the general population. High alcohol intake, especially of beer, is also a factor of importance for hyperuricemia and gout, while intake of wine rather seems to be protective [25]. According to the OECD statistics, alcohol intake per capita was highest in Estonia and Austria in 2012, with Hungary, Russia and Germany ranked on the seventh to ninth places, and with a very low alcohol intake in Turkey [26]. However, pattern of intake of the different alcohol beverages differ, with a high intake of beer in inhabitants not only in Austria, Germany, Finland, Poland, Hungary, Russia and the Netherlands but also in Spain; a high intake of spirits in Russia, Hungary and Poland; and a high intake of wine and relatively lower of other alcohol beverages in France, Greece, Italy and 
Table 5 The risk of gout in second-generation female immigrants

\begin{tabular}{|c|c|c|c|c|}
\hline Country/region of origin & $\begin{array}{l}\text { Model } 1 \\
\text { HR }(95 \% \text { CI) }\end{array}$ & $\begin{array}{l}\text { Model } 2 \\
\text { HR (95\% CI) }\end{array}$ & $\begin{array}{l}\text { Model } 3 \\
\text { HR (95\% CI) }\end{array}$ & $\begin{array}{l}\text { Model } 4 \\
\text { HR (95\% CI) }\end{array}$ \\
\hline Sweden & 1 (ref) & 1 (ref) & 1 (ref) & 1 (ref) \\
\hline Nordic countries & $0.88(0.76-1.03)$ & $0.84(0.72-0.98)$ & $0.82(0.70-0.96)$ & $0.83(0.71-0.97)$ \\
\hline Denmark & $0.74(0.50-1.10)$ & $0.69(0.47-1.03)$ & $0.69(0.47-1.02)$ & $0.74(0.50-1.09)$ \\
\hline Finland & $0.94(0.77-1.14)$ & $0.90(0.74-1.09)$ & $0.87(0.72-1.06)$ & $0.85(0.70-1.04)$ \\
\hline Norway & $0.89(0.65-1.21)$ & $0.85(0.62-1.17)$ & $0.85(0.62-1.16)$ & $0.87(0.64-1.20)$ \\
\hline Southern Europe & $0.79(0.42-1.47)$ & $0.70(0.38-1.31)$ & $0.67(0.36-1.25)$ & $0.77(0.41-1.44)$ \\
\hline Greece & $0.75(0.24-2.33)$ & $0.62(0.20-1.94)$ & $0.59(0.19-1.84)$ & $0.72(0.23-2.23)$ \\
\hline Italy & $0.49(0.12-1.98)$ & $0.45(0.11-1.81)$ & $0.43(0.11-1.74)$ & $0.52(0.13-2.09)$ \\
\hline Spain & $1.17(0.29-4.70)$ & $1.08(0.27-4.31)$ & $1.04(0.26-4.16)$ & $1.04(0.26-4.17)$ \\
\hline Western Europe & $0.70(0.49-1.01)$ & $0.70(0.49-1.01)$ & $0.69(0.48-0.99)$ & $0.76(0.53-1.09)$ \\
\hline The Netherlands & $0.87(0.22-3.48)$ & $0.84(0.21-3.36)$ & $0.82(0.20-3.27)$ & $0.96(0.24-3.83)$ \\
\hline UK and Ireland & $1.06(0.44-2.55)$ & $1.01(0.42-2.42)$ & $0.97(0.40-2.34)$ & $1.06(0.44-2.55)$ \\
\hline Germany & $0.64(0.40-1.02)$ & $0.65(0.41-1.03)$ & $0.64(0.40-1.01)$ & $0.70(0.44-1.11)$ \\
\hline Austria & $0.68(0.22-2.09)$ & $0.69(0.22-2.14)$ & $0.68(0.22-2.10)$ & $0.74(0.24-2.30)$ \\
\hline Eastern Europe & $1.11(0.69-1.79)$ & $1.03(0.64-1.67)$ & $0.99(0.62-1.61)$ & $1.01(0.62-1.63)$ \\
\hline Yugoslavia & $0.94(0.50-1.75)$ & $0.86(0.46-1.60)$ & $0.84(0.45-1.56)$ & $0.88(0.47-1.63)$ \\
\hline Romania & $2.30(0.74-7.13)$ & $2.28(0.74-7.08)$ & $2.21(0.71-6.85)$ & $2.07(0.67-6.42)$ \\
\hline Baltic countries & $1.15(0.73-1.80)$ & $1.19(0.76-1.86)$ & $1.16(0.74-1.82)$ & $1.22(0.77-1.91)$ \\
\hline Estonia & $1.06(0.64-1.77)$ & $1.09(0.66-1.82)$ & $1.07(0.64-1.78)$ & $1.13(0.68-1.87)$ \\
\hline Latvia & $1.62(0.61-4.33)$ & $1.77(0.66-4.71)$ & $1.72(0.64-4.58)$ & $1.78(0.67-4.75)$ \\
\hline Central Europe & $1.28(0.82-1.99)$ & $1.27(0.82-1.97)$ & $1.26(0.81-1.96)$ & $1.25(0.81-1.95)$ \\
\hline Poland & $1.20(0.62-2.30)$ & $1.19(0.62-2.29)$ & $1.18(0.61-2.26)$ & $1.12(0.58-2.16)$ \\
\hline Other Central Europe & $1.28(0.48-3.42)$ & $1.28(0.48-3.42)$ & $1.27(0.48-3.38)$ & $1.33(0.50-3.54)$ \\
\hline Hungary & $1.42(0.67-2.97)$ & $1.41(0.67-2.96)$ & $1.40(0.67-2.95)$ & $1.45(0.69-3.05)$ \\
\hline North America & $0.75(0.41-1.35)$ & $0.75(0.42-1.36)$ & $0.74(0.41-1.34)$ & $0.80(0.44-1.44)$ \\
\hline Latin America & $1.32(0.59-2.94)$ & $1.17(0.52-2.61)$ & $1.12(0.50-2.50)$ & $1.05(0.47-2.35)$ \\
\hline South America & $1.62(0.52-5.04)$ & $1.47(0.47-4.57)$ & $1.42(0.46-4.40)$ & $1.42(0.46-4.41)$ \\
\hline Asia & $1.42(0.95-2.11)$ & $1.25(0.83-1.86)$ & $1.18(0.79-1.77)$ & $1.10(0.74-1.65)$ \\
\hline Turkey & $2.04(1.13-3.70)$ & $1.74(0.96-3.16)$ & $1.66(0.91-3.01)$ & $1.61(0.89-2.92)$ \\
\hline Iran & $0.40(0.06-2.79)$ & $0.37(0.05-2.62)$ & $0.36(0.05-2.52)$ & $0.32(0.05-2.24)$ \\
\hline Iraq & $1.38(0.44-4.30)$ & $1.18(0.38-3.67)$ & $1.09(0.35-3.41)$ & $0.94(0.30-2.94)$ \\
\hline Other Asian countries & $1.70(0.91-3.17)$ & $1.54(0.83-2.88)$ & $1.48(0.79-2.76)$ & $1.42(0.76-2.66)$ \\
\hline Russia & $0.92(0.38-2.21)$ & $0.93(0.39-2.23)$ & $0.91(0.38-2.19)$ & $0.87(0.36-2.09)$ \\
\hline
\end{tabular}

Regions (also including separately listed countries) marked by italicsHR (95\% CI): Hazard ratios with 95\% confidence intervalStatistically significant HRs marked by italics Model 1: adjusted for age and region of residence in Sweden; model 2: adjusted for age, region of residence in Sweden, educational level and marital status; model 3: model $2+$ neighbourhood deprivation; model 4: model $3+$ co-morbidities
Chile. Immigrants probably bring drinking habits from their country of origin, which is why the alcohol intake patterns of home countries is of importance. Thus, high intake of beer or spirits could partly explain the higher risk of gout among immigrants from Finland, Austria, Poland, Hungary and Russia.

The increased prevalence of gout and hyperuricemia in both Western and third-world societies has been linked not only to urbanization, western lifestyle and immigration to western countries [27] but also to higher rates of hypertension [28]. The increased incidence and prevalence of gout worldwide tails the obesity epidemic [11]. Even if gout has been regarded as "the disease of kings" and as such associated to wealth and good living [29], it is nowadays more linked to lower socio-economic status [30], which is also in line with our findings. The risk of overweight and obesity, especially abdominal obesity, has been shown to be higher in many immigrant groups of non-European origin [31]. Among nonWestern immigrants, Middle East women in general have a higher risk of abdominal obesity [32] and diabetes [33]. When looking at dietary patterns among immigrants, also including second-generation immigrants, a pattern with more sugar-rich food and beverages and more fat-rich food is seen [31]. In 
general, it seems that dietary habits among non-Western immigrant groups in Europe are likely to become less healthy [34]. Dietary habits among second-generation immigrants also tend to approach those found in age- and sex-matched individuals in the indigenous population [35]. In contrast, the prevalence of hypertension is lower among immigrants of non-European origin in Sweden [36], i.e. one important factor that could explain the lower risk of gout among some groups. As hyperuricemia and gout also is associated with CVD and CHD, patterns of these among different countries are of importance. According to recent statistics from the OECD, the CHD mortality is higher in Finland, the Baltic countries, Eastern Europe, Hungary and Turkey than in Sweden; while a lower CHD mortality is reported from the Nordic countries with the exception of Finland, Southern Europe and Chile [37].

When looking at the specific immigrant groups and the risk of gout, among Turkish born women an increased risk of abdominal obesity and the metabolic syndrome [38] and also of diabetes [39], has been reported. Besides, among Iraqi immigrants, an increased risk of pre-diabetes and diabetes has been reported [40]. A higher risk of abdominal obesity is also found among immigrants, especially in women, from Eastern Europe, in that study also, including immigrants from Poland, Hungary and Russia [32], and a higher body mass index (BMI) among Polish men [41]. The lower estimates in some of these groups when adjusting for co-morbidities could support that obesity may partly explain the excess risk. Otherwise, the estimates were only marginally changed when adjusting for co-morbidities. As regards the lower risk of gout among South Europeans, adherence to Mediterranean diet is associated with a lower risk of hyperuricemia [42].

There are some limitations in this study. As we divided into many different immigrant groups, there is a risk of mass significance when using the $p$ level $<0.05$. Thus, the results should be interpreted with caution owing to the multiple testing. The statistical power to detect significant results also differed between the immigrant groups owing to varying sample size, and the power was lower among women, especially second-generation women. We used hospital diagnoses to identify individuals with gout, and it is possible that other groups would have been identified if we had access to diagnoses in other care forms, especially primary care. As diagnoses were taken from the National Patient Register, they are clinically based and we cannot check for the criteria for gout diagnosis being used. Furthermore, we had no access to prescription of allopurinol, but when this was actual, the diagnosis was probably set. We adjusted for co-morbidities which can be discussed as the association between gout and co-morbidities may go in both directions, i.e. may be a risk factor for gout or a consequence of gout. However, results when adjusted for comorbidities were similar in most cases. Despite the limitations, this is one of rare studies in Europe providing insight in differences in gout among different immigrant groups. A strength of the study is that we used neighbourhood SES that is a proxy for lifestyle factors [43], and it has been shown to be associated with, for example smoking [44, 45].

In conclusion, the results of this study indicate significant differences in risks of gout between immigrants and Swedish-born groups, which are more prominent between first-generation immigrant men and women and their Swedish counterparts. As gout is a risk factor for cardio-vascular diseases, including an increased mortality risk [10], identifying patients with hyperuricemia and gout is one way to be able to prevent these diseases. The differences observed may be related to differences between immigrants and Swedish born in the interplay between genetics and environment, risk factors for gout or provision of medical care. As gout causes suffering for the individuals and increased cost for society, measures in preventing gout, especially by healthier lifestyle habits, could be an effective way to entangle the problem. As the risk of gout is increased among some immigrant groups, it is important to draw attention to this, to reassure equity in health in the population. A healthier lifestyle in the whole population is desirable, but to reach this goal, interventions might need to be tailored for specific groups.

Acknowledgements This project was supported by grants to Kristina Sundquist and Jan Sundquist from the Swedish Research Council for Health, Working Life and Welfare (In Swedish: Forte; Reg.nr: 20131836; 2014-0804), the Swedish Research Council (2012-2378; 201410134) and the ALF funding from Region Skåne that was awarded to them.

Contribution Planning: Per Wändell, Axel C Carlsson and Xinjun Li. Access to data: Xinjun Li, Jan Sundquist and Kristina Sundquist. Statistical analysis: Xinjun Li. Drafting of manuscript: Per Wändell. Reading and commenting manuscript: all authors.

Compliance with ethical standards The study was approved by the local ethical vetting board at the Karolinska Institutet (reference number 12/00 EPN Huddinge at 6 March 2000, approval of addition at 18 November 2002).

\section{Disclosures None.}

Funding information This work was supported by grants to Kristina Sundquist and Jan Sundquist from the Swedish Research Council for Health, Working Life and Welfare, and the Swedish Research Council as well as the ALF funding to Jan Sundquist and Kristina Sundquist from the Region Skåne.

Open Access This article is distributed under the terms of the Creative Commons Attribution 4.0 International License (http:// creativecommons.org/licenses/by/4.0/), which permits unrestricted use, distribution, and reproduction in any medium, provided you give appropriate credit to the original author(s) and the source, provide a link to the Creative Commons license, and indicate if changes were made. 


\section{References}

1. Roddy E, Choi HK (2014) Epidemiology of gout. Rheum Dis Clin N Am 40(2):155-175. doi:10.1016/j.rdc.2014.01.001

2. Chandratre P, Roddy E, Clarson L, Richardson J, Hider SL, Mallen CD (2013) Health-related quality of life in gout: a systematic review. Rheumatology (Oxford) 52(11):2031-2040. doi:10.1093/rheumatology/ket265

3. Nakamura K, Sakurai M, Miura K, Morikawa Y, Nagasawa SY, Ishizaki M, Kido T, Naruse Y, Nakashima M, Nogawa K, Suwazono Y, Nakagawa H (2014) HOMA-IR and the risk of hyperuricemia: a prospective study in non-diabetic Japanese men. Diabetes Res Clin Pract 106(1):154-160. doi:10.1016/j. diabres.2014.07.006

4. Li C, Hsieh MC, Chang SJ (2013) Metabolic syndrome, diabetes, and hyperuricemia. Curr Opin Rheumatol 25(2):210-216. doi:10.1097/BOR.0b013e32835d951e

5. Zhu Y, Pandya BJ, Choi HK (2012) Comorbidities of gout and hyperuricemia in the US general population: NHANES 2007-2008. Am J Med 125(7):679-687 . doi:10.1016/j. amjmed.2011.09.033e671

6. Gibson TJ (2013) Hypertension, its treatment, hyperuricaemia and gout. Curr Opin Rheumatol 25(2):217-222. doi:10.1097/BOR.0 b013e32835cedd4

7. Reungjui S, Pratipanawatr T, Johnson RJ, Nakagawa T (2008) Do thiazides worsen metabolic syndrome and renal disease? The pivotal roles for hyperuricemia and hypokalemia. Curr Opin Nephrol Hypertens 17(5):470-476. doi:10.1097/MNH.0b013e328305b9a5

8. Sica DA, Carter B, Cushman W, Hamm L (2011) Thiazide and loop diuretics. J Clin Hypertens (Greenwich) 13(9):639-643. doi:10.1111/j.1751-7176.2011.00512.x

9. Wijnands JM, Viechtbauer W, Thevissen K, Arts IC, Dagnelie PC, Stehouwer CD, van der Linden S, Boonen A (2015) Determinants of the prevalence of gout in the general population: a systematic review and meta-regression. Eur J Epidemiol 30(1):19-33. doi:10.1007/s10654-014-9927-y

10. Kim SY, De Vera MA, Choi HK (2008) Gout and mortality. Clin Exp Rheumatol 26(5 Suppl 51):S115-S119

11. Roddy E, Zhang W, Doherty M (2007) The changing epidemiology of gout. Nat Clin Pract Rheumatol 3(8):443-449. doi:10.1038/ncprheum0556

12. Vamvakas S, Teschner M, Bahner U, Heidland A (1998) Alcohol abuse: potential role in electrolyte disturbances and kidney diseases. Clin Nephrol 49(4):205-213

13. Kaneko K, Aoyagi Y, Fukuuchi T, Inazawa K, Yamaoka N (2014) Total purine and purine base content of common foodstuffs for facilitating nutritional therapy for gout and hyperuricemia. Biol Pharm Bull 37(5):709-721

14. Mikuls TR, Farrar JT, Bilker WB, Fernandes S, Schumacher HR Jr, Saag KG (2005) Gout epidemiology: results from the UK General Practice Research Database, 1990-1999. Ann Rheum Dis 64(2): 267-272. doi:10.1136/ard.2004.024091

15. Annemans L, Spaepen E, Gaskin M, Bonnemaire M, Malier V, Gilbert T, Nuki G (2008) Gout in the UK and Germany: prevalence, comorbidities and management in general practice 2000-2005. Ann Rheum Dis 67(7):960-966. doi:10.1136/ard.2007.076232

16. Kuo CF, Grainge MJ, Zhang W, Doherty M (2015) Global epidemiology of gout: prevalence, incidence and risk factors. Nat Rev Rheumatol 11(11):649-662. doi:10.1038/nrrheum.2015.91

17. Statistics Sweden (2016) Foreign-born persons in Sweden by country of birth, age and sex. Year 2000-2015. In: ed. Statistics Sweden

18. Ludvigsson JF, Andersson E, Ekbom A, Feychting M, Kim JL, Reuterwall C, Heurgren M, Olausson PO (2011) External review and validation of the Swedish national inpatient register. BMC Public Health 11:450. doi:10.1186/1471-2458-11-450
19. Winkleby M, Sundquist K, Cubbin C (2007) Inequities in CHD incidence and case fatality by neighborhood deprivation. Am J Prev Med 32(2):97-106. doi:10.1016/j.amepre.2006.10.002

20. Zoller B, Li X, Sundquist J, Sundquist K (2013) Neighbourhood deprivation and hospitalization for atrial fibrillation in Sweden. Europace 15(8):1119-1127. doi:10.1093/europace/eut019

21. Kuo CF, Grainge MJ, See LC, Yu KH, Luo SF, Zhang W, Doherty M (2015) Epidemiology and management of gout in Taiwan: a nationwide population study. Arthritis Res Ther 17:13. doi:10.1186/s13075-015-0522-8

22. Wandell P, Carlsson AC, Ljunggren G (2015) Gout and its comorbidities in the total population of Stockholm. Prev Med 81:387391. doi:10.1016/j.ypmed.2015.10.003

23. Torralba TP, Bayani-Sioson PS (1975) The Filipino and gout. Semin Arthritis Rheum 4(4):307-320

24. Hak AE, Choi HK (2008) Lifestyle and gout. Curr Opin Rheumatol 20(2):179-186. doi:10.1097/BOR.0b013e3282f524a2

25. Choi HK, Atkinson K, Karlson EW, Willett W, Curhan G (2004) Alcohol intake and risk of incident gout in men: a prospective study. Lancet 363(9417):1277-1281. doi:10.1016/S0140-6736 (04)16000-5

26. OECD (2015) Tackling harmful alcohol use: economics and public health policy. OECD Publishing

27. Johnson RJ, Titte S, Cade JR, Rideout BA, Oliver WJ (2005) Uric acid, evolution and primitive cultures. Semin Nephrol 25(1):3-8

28. Hochberg MC, Thomas J, Thomas DJ, Mead L, Levine DM, Klag MJ (1995) Racial differences in the incidence of gout. The role of hypertension. Arthritis Rheum 38(5):628-632

29. Richette P, Bardin T (2010) Gout. Lancet 375(9711):318-328. doi:10.1016/S0140-6736(09)60883-7

30. Kuo CF, Grainge MJ, Mallen C, Zhang W, Doherty M (2015) Rising burden of gout in the UK but continuing suboptimal management: a nationwide population study. Ann Rheum Dis 74(4): 661-667. doi:10.1136/annrheumdis-2013-204463

31. Wandell PE (2013) Population groups in dietary transition. Food Nutr Res 57 DOI 10.3402/fnr.v57i0.21668

32. Carlsson AC, Wandell P, Riserus U, Arnlov J, Borne Y, Engstrom G, Leander K, Gigante B, Hellenius ML, de Faire U (2014) Differences in anthropometric measures in immigrants and Swedish-born individuals: results from two community-based cohort studies. Prev Med 69:151-156. doi:10.1016/j.ypmed.2014.09.020

33. Wandell PE, Carlsson A, Steiner KH (2010) Prevalence of diabetes among immigrants in the Nordic countries. Curr Diabetes Rev 6(2): 126-133

34. Gilbert PA, Khokhar S (2008) Changing dietary habits of ethnic groups in Europe and implications for health. Nutr Rev 66(4): 203-215. doi:10.1111/j.1753-4887.2008.00025.x

35. Hrboticky N, Krondl M (1984) Acculturation to Canadian foods by Chinese immigrant boys: changes in the perceived flavor, health value and prestige of foods. Appetite 5(2):117-126

36. Carlsson AC, Wandell PE, de Faire U, Hellenius ML (2008) Prevalence of hypertension in immigrants and Swedish-born individuals, a cross-sectional study of 60 -year-old men and women in Sweden. J Hypertens 26(12):2295-2302

37. OECD (2015) Mortality from cardiovascular diseases. In: Health at a glance 2015: OECD indicators ed. OECD Publishing, pp50-51

38. Daryani A, Berglund L, Andersson A, Kocturk T, Becker W, Vessby B (2005) Risk factors for coronary heart disease among immigrant women from Iran and Turkey, compared to women of Swedish ethnicity. Ethn Dis 15(2):213-220

39. Hjorleifsdottir-Steiner K, Satman I, Sundquist J, Kaya A, Wandell P (2011) Diabetes and impaired glucose tolerance among Turkish immigrants in Sweden. Diabetes Res Clin Pract 92(1):118-123. doi:10.1016/j.diabres.2010.12.011 
40. Bennet L, Johansson SE, Agardh CD, Groop L, Sundquist J, Rastam L, Sundquist K (2011) High prevalence of type 2 diabetes in Iraqi and Swedish residents in a deprived Swedish neighbourhood - a population based study. BMC Public Health 11:303. doi:10.1186/1471-2458-11-303

41. Wandell PE, Ponzer S, Johansson SE, Sundquist K, Sundquist J (2004) Country of birth and body mass index: a national study of 2,000 immigrants in Sweden. Eur J Epidemiol 19(11):1005-1010

42. Kontogianni MD, Chrysohoou C, Panagiotakos DB, Tsetsekou E, Zeimbekis A, Pitsavos C, Stefanadis C (2012) Adherence to the Mediterranean diet and serum uric acid: the ATTICA study. Scand J Rheumatol 41(6):442-449. doi:10.3109/03009742.2012.679964
43. Cubbin C, Winkleby MA (2005) Protective and harmful effects of neighborhood-level deprivation on individual-level health knowledge, behavior changes, and risk of coronary heart disease. Am J Epidemiol 162(6):559-568. doi:10.1093/aje/kwi250

44. Douglas L, Szatkowski L (2013) Socioeconomic variations in access to smoking cessation interventions in UK primary care: insights using the Mosaic classification in a large dataset of primary care records. BMC Public Health 13:546. doi:10.1186/1471-245813-546

45. Sharma A, Lewis S, Szatkowski L (2010) Insights into social disparities in smoking prevalence using Mosaic, a novel measure of socioeconomic status: an analysis using a large primary care dataset. BMC Public Health 10:755. doi:10.1186/1471-2458-10-755 